\title{
Erratum to: New anti-inflammatory flavonoids from Cadaba glandulosa Forssk
}

Gamal A. Mohamed • Sabrin R. M. Ibrahim •

Nawal M. Al-Musayeib · Samir A. Ross

Published online: 15 January 2014

(C) The Pharmaceutical Society of Korea 2014

\section{Erratum to: Arch Pharm Res \\ DOI 10.1007/s12272-013-0305-1}

In the original version of the article entitled "New antiinflammatory flavonoids from Cadaba glandulosa Forssk", published in (DOI 10.1007/s12272-013-0305-1), unfortunately some errors were made by the authors. These errors should be corrected as below:
In Introduction section:

Line 1: The word 'farinosa' should be corrected to 'glandulosa'.

Line 13: The word 'Chamaecrista' should be corrected to 'Cadaba'.

The online version of the original article can be found under doi:10.1007/s12272-013-0305-1.

\section{G. A. Mohamed}

Department of Natural Products and Alternative Medicine, Faculty of Pharmacy, King Abdulaziz University,

Jeddah 21589, Kingdom of Saudi Arabia

\section{G. A. Mohamed}

Department of Pharmacognosy, Faculty of Pharmacy,

Al-Azhar University, Assiut Branch, Assiut 71524, Egypt

\section{S. R. M. Ibrahim}

Department of Pharmacognosy, Faculty of Pharmacy,

Assiut University, Assiut 71526, Egypt

\section{N. M. Al-Musayeib}

Department of Pharmacognosy, Faculty of Pharmacy,

King Saud University, Riyadh 11451, Saudi Arabia

\section{S. A. Ross $(\square)$}

National Center for Natural Products Research, Department of Pharmacognosy School of Pharmacy, University of Mississippi, MS 38677, USA

e-mail: sross@olemiss.edu 